philosophical perspective its authors are well informed not only about developments within biomedicine but also about anthropological and psychosocial accounts of biomedicine. The issues raised are 'live' issues. It is an unhappy fact that many British philosophers who have addressed issues of health, illness and medicine have had only a superficial awareness of the substantial body of research on health paradigms, behaviour and policy. And second, it is unusual because it draws on a broad range of philosophical approaches, Anglo-Saxon and European, in an attempt to clarify and illuminate the issues selected for discussion. It is a bonus for someone like this reviewer - who is unfamiliar with recent contributions from the Netherlands that the theses of a number of Dutch philosophers and analysts are introduced and dissected.

The book starts well with a crisp and authoritative introduction that reflects the authors' knowledge of work in a range of disciplines, from the medical to the behavioural and social sciences to philosophy. If anything, perhaps too much is promised. This is followed by five key chapters, dealing with 'cultural infusions in the philosophy of medicine', 'regular versus alternative medicine', 'concepts of health and disease', 'mind and body in science and philosophy' and 'mind and body in science'. Within these 'contexts' several themes recur: the salience of the cultural and the normative to medical science and practice; the significant but limited role of common sense in and around medicine; the lack of an integrative theory of mind and body, in medicine and elsewhere; the inadequacies of extant concepts of stress; and the neglect of ecology, 'as a discipline of biology', in medicine. There is strong support for the views that the 'achievements of medicine are but a minor factor in improving health at the population level', and that 'philosophy of medicine had better take this into account'.

Apart from appreciating its unusual features, I was extremely sympathetic both to the stance adopted by the authors and to the areas and issues chosen for analysis. The analysis itself is generally concise and clear. What is perhaps disappointing is that the authors are more adept at highlighting problems and exposing possible flaws in the arguments of others than they are at advancing constructive alternatives. They are inclined to hint at rather than pursue promising avenues of enquiry. Indeed, some Anglo-Saxon philosophers will find their very succinctness frustrating. Less charitably, they might be accused of avoiding sustained argument.

This is an interesting book which undermines or questions much orthodox thinking in medicine and sets an apt and challenging agenda for future healing. The qualification that it will be up to others to develop and supplement positive arguments for items on this agenda should certainly not dissuade those committed to healing from reading it.

GRAHAM SCAMBLER Senior Lecturer in Sociology Department of Psychiatry, University College, London

\section{Terminal Choices: Euthanasia, Suicide, and the Right to Die}

Robert N Wennberg, 246 pages, Grand Rapids, Michigan, USA, $\$ 13.95$, Wm B Eerdmans, 1989.

The title of this book gives no indication that the author, Professor of Philosophy at Westmont College, Santa Barbara, California, is also an ordained Presbyterian minister who therefore writes, with appropriate philosophical detachment, from an explicitly Christian perspective. While he is also on the ethics committee of Cottage Hospital, Santa Barbara, he is not personally involved in the provision of health care, and he consequently states that he begins with a focus on the patient, who, rather than the professional, is viewed as the 'central moral agent'.

As a result he sees the fundamental issue as being that of suicide and he devotes a chapter to its delineation in moral terms from other forms of voluntary dying. He then proceeds to discuss its ethical implications, to consider 'surcease suicide' (defined as suicide committed to avoid grave personal harm), passive euthanasia, the status of the permanently unconscious patient, and finally the problems postulated as arising with the possibility of the legalisation of voluntary active euthanasia. He ends with a bibliography of over 200 books and articles, but three-quarters of these are at least a decade old, and none of the articles quoted are from within the last five years, which inevitably gives rise to a somewhat dated impression.
His restriction of the use of the word 'suicide' to acts resulting from a conscious desire for death, which forms the basis of his formulation of an 'intent' to die, is confusing as it does not correspond to the usual legal distinction between intent and motivation. He specifically rejects the common sense or legal presumption that one should be deemed to have intended all the foreseen results of one's actions, preferring to distinguish between direct and indirect killings according to the principle of double effect. This may not appeal to the secular reader.

He makes some interesting points, as when he differentiates ordinary and extraordinary treatments according to the quality of the suffering entailed rather than the nature of the therapy, and when he draws an analogy between society's prohibition of euthanasia and of duelling: both activities involve the voluntary relinquishment of the right to life by consenting parties. His tone is kindly and his arguments measured, but while his commitment to a religious faith may put a more adequate emphasis on human relationships and connectedness than do recent writings stressing individual autonomy, the book is perhaps more likely to appeal as a source of philosophical support to those who already feel at home within a Christian framework than to influence the thinking or practice of those who would place themselves outside that tradition.

TIM HELME

Locum Senior Registrar in Forensic Psychiatry,

6 Rivermill, 151 Grosvenor Road, London SWIV 3YN

\section{Danish Medical Bulletin: Journal of Medical, Dental and Pharmaceutical Sciences: Supplement No 1}

Edited by Ole Vedel Rasmussen, 88 pages, Denmark, free of charge for foreign medical institutions on request: Danish Medical Association, Trondhjemsgade 9, Dk-2100, Copenhagen 0, Denmark, Ugeskrift for Laeger, 1990

It is a distressing reflection of our times that the use of torture is still practised - 